MIECZYSŁAW LUBAŃSKI

\title{
CONSERVATIVE AND PROGRESSIVE COMPONENTS IN SCIENCE*
}

\begin{abstract}
The development of science, proceeding at a higher and higher speed, leads to the creation of new concepts, theories, and ideas. They constitute a progressive component of science. However, scientific development does not mean that everything that was accepted earlier has to be given up. New elements may be acquired and exist together with the old ones. Such old elements constitute a conservative component of science. That is why modern science shows itself as a wholeness constituted by the above-mentioned components.
\end{abstract}

Keywords: science; history of science; development

1. Introduction. 2. External characteristics of the development of science. 3. Progress in science. 4. Permanent elements in science. 5. Differentiation of science and its unity. 6. Conclusions.

\section{INTRODUCTION}

Science is developing faster and faster. No field of research remains unchanged; it is constantly developing, and new fields of knowledge are emerging. Examples of such scientific disciplines include, among others, general systems theory, cybernetics, information theory, automata theory, computer science etc. Experience shows that an individual researcher is not able to remember the results obtained from even one specific field of science forever. This is due to the fact that hundreds of new concepts, theories and ideas are created all the time. This naturally leads to the question related to the essential characteristics of science, in particular, of whether progress tells us to reject

* This article was originally published in Polish as: M. Lubański, Składowa zachowawcza i postepowa w nauce, Studia Philosophiae Christianae 36(2000)2, 125-136. The translation of the article into English was financed by the Ministry of Science and Higher Education of the Republic of Poland as part of the activities promoting science - Decision No. 676/P-DUN/2019 of 2 April 2019. Translation made by GROY Translations. 
everything that is old and not present, or whether there are certain elements that have become lasting achievements of science. The aim of this article is to present and discuss the above-mentioned issue.

\section{EXTERNAL CHARACTERISTICS OF THE DEVELOPMENT OF SCIENCE}

The development of science is often associated with an increase in the number of publications appearing in a particular field of research. The appearance of the printed book contributed to a wider dissemination of scientific achievements, which , in turn, led to the need for making continuous publications. History recorded that the first scientific journals started to be published in the second half of the 17th century. Namely, in January 1665, Journal des Scavans was printed, and then The Philosophical Transactions of the Royal Society of London in March of that year. Quite a significant development of scientific periodicals took place in the second half of the 18th century. In the next century, three groups of journals were formed: general, semi-general and specialist journals. Around 1830 the number of journals reached 300. This number was considered to be critical; this means that no scholar was able to read all the papers published ${ }^{1}$. Therefore, the need for journals that would review publications (books and scientific articles) appearing in a specific field of knowledge emerged naturally. The first journal of this kind was Chemisches Zentralblatt which was published for the first time in 1830. And here history repeated itself as well. New review journals dedicated to specific fields or disciplines of knowledge began to emerge. Their number was gradually increasing. Another critical point was reached around 1950. The number of review journals reached 300 . It will not be a mistake if we say that nowadays every important field of research has its own review journal. The number of different types of journals is constantly growing. And that

1 J. Ratajewski, Wstęp do informacji naukowej, Katowice 1973, 19; M. Uklejska, Zarys rozwoju nauki i jej organizacji, Część II: Czasy nowożytne, Warszawa 1963, 244; D. J. de Solla Price, Węzłowe problemy historii nauki, transl. H. Krahelska, Warszawa 1965, 99. 
is where the "problem of information" occurs. In short, the problem concerns having quick access to valuable information.

This is where theoretical science is linked to information technology, which is incomparably more efficient in finding new information that we need than it was possible in the past. At the same time, there is a suggestion to use the so called information model of science that shows how important the information element is in scientific development, which helps us better understand the very essence of science.

Let us recall that according to the above-mentioned model, science is a complex, self-organized system the development of which is controlled by information streams. Therefore, if science, as a system, is enriched with new information, it means it is being developed; the lack of new information, on the other hand, prevents science from developing, i.e. leads to its stagnation ${ }^{2}$.

If scientific publications are treated as carriers of information, their growth will be an indication of scientific development. Due to the relatively young age of science, in the modern sense of this term, we are dealing with an exponential increase in publications. This applies to both the macroscale, i.e. when it comes to a specific scientific discipline, and the microscale - when it comes to a particular direction of research in the discipline in question. From a theoretical point of view, the development of science may - and even should - follow the exponential curve. In practice, however, this is unrealistic for a variety of reasons such as, for instance, the emergence of new fields of research, as a result of which scientists abandon older research, increasing costs of more and more specialized research, and unpredictable occurrence of external factors (wars, epidemics, etc.). Therefore, it is assumed that the development of science is exponential to a certain point; then it reaches a stage characterized by a logistic curve that has an asymptote parallel to the timeline. Usually, the situation occurring here is determined by saying that the exponential curve evolves into a logistic curve if the so-called damping factors occur. As far as the logistic

2 W. W. Nalimow, Z. M. Mulczenko, Naukometria, transl. S. Zasada, Warszawa 1971, 6, 10. 
curve is concerned, there is the so-called inflection point, i.e. the point at which the rate of scientific development ceases to grow and begins to slow down because the logistic curve goes towards its asymptote ${ }^{3}$.

We will not analyze in detail at which point of development a particular scientific discipline is right now. It is not the purpose of this article. We only point out to the huge development of scientific literature, which proves that science does not stand still. To put it briefly, it should be said that science is developing in all directions. It is worth reminding at this point that forty years ago, the then stage of science was called Big Science as opposed to the previous one, known as Little Science. The use of such terms was justified by the fact that scientists living at that time represented from $60 \%$ to $90 \%$ of all the scientists who had ever lived before. This estimation seems to be true also at the moment. Moreover, scientific achievements of the current generation of scientists represent at least $80 \%$ of all the achievements ever made. Therefore, science is fully modern within the proper meaning of the last term. It can be called Big Science, which, however, is only seen as a transitional stage leading to a new period, which should most appropriately be called New Science 4 .

Given the above, the development of science is undoubtedly a fact, which immediately leads us to the concept of progress in science. But, what does progress in science really mean? What is it? Let us discuss this issue now.

\section{PROGRESS IN SCIENCE}

Research experience shows that progress in science can manifest itself in many ways. It includes the achievement of greater precision of specialist concepts functioning in a given research discipline or direction. It may also involve encompassing several specific creations with a single formal form; modern algebra, which has highlighted the variety and richness of mathematical systems for the first time,

3 Ibid, 17-18.

4 D. J. de Solla Price, Węzłowe problemy historii nauki, op. cit., 36-37. 
is a good example ${ }^{5}$. It may also involve the development of a new field of research, which has emerged as the final result of reflections on a technical invention. The theory of information has to be mentioned at this point. Its origins should be associated with the invention of electric telegraph by S. B. F. Morse in 1832. The theoretical reflection on the relationship between the speed of telegraphing and the number of current values used resulted in creating the concept of the capacity of information; this in turn led to the concept of the quantities of information. As a result, C. E. Shannon described the research conducted in this field for more than one hundred years, in his paper entitled $A$ mathematical theory of communication, which was published in 1948. It is interesting that the title of the above-mentioned publication, which was a mathematical theory of communication, i.e. communication between people, was changed into the theory of information. The new title was rather exaggerated. Shannon's paper was that of a telecommunications engineer. And telecommunications engineers are not interested in the content of transmitted information, but in a purely technical matter, namely faithful transmission of signals so that the recipient, especially the one located far away from the sender, receives them without distortions.

After presenting these rather general remarks, let us take a closer look at one particular example, which, as it may be assumed, indicates the progress achieved, i.e. the concept of infinity. Although its origins go back to antiquity, it is still used today. For this purpose, let us consider the following four concepts of an infinite set:

(A) An infinite set is a set to which a new element can always be added from the outside. A set which has no elements that can be added from the outside is finite and complete ${ }^{6}$.

(B) An infinite set is a set that is larger than every finite set, i.e. every finite set is part of an infinite set ${ }^{7}$.

5 G. Birkhoff, S. Mac Lane, Przegląd algebry współczesnej, transl. A. Ehrenfeucht, A. W. Mostowski, Warszawa 1966, 9.

6 Arystoteles, Fizyka, transl. K. Leśniak, Warszawa 1968, 88n (206b-207a).

7 B. Bolzano, Paradoxes of Infinity, transl. F. Prihonsky, Yale University Press, New Haven 1950, 4. 
(Z) A set is called finite if it is equinumerous to a set of natural numbers $\{1,2, \ldots, n\}$ for certain natural $n$. Otherwise, the set is said to be infinite ${ }^{8}$.

(D) According to Dedekind, a set is called infinite if it contains a specific subset that is equinumerous to it ${ }^{9}$.

It is not difficult to notice that, according to statement (A), the infinite nature of a set consists in its infinity, in having no limit, boundary, or end. It is not possible to reach the limit, boundary or end of the set. There is always something else. And so on. If we come across the limit of a given set, it means that the set in question is finite. In other words, if a set exists within its limits, then it is a finite set. If a set can be continuously extended, it does not exist within its finite limits, so (as an infinite set) it is something possible, potential. Therefore, it may be said that the term "set" within the meaning presented in statement (A) attributes actual existence only to finite sets and potential existence only to infinite sets. Consequently, the statement proclaiming the potentiality of infinity would be, strictly speaking, not a thesis, but a definition.

It should be noted at this point that the above reasoning cannot be regarded as entirely precise. It uses an intuitive, common understanding of the terms: limit of a set, boundary of a set, end of a set. Today, we distinguish between these terms and have precise definitions. It is therefore possible to formulate comments on statement (A) in precise terms. However, we do not do this just because we do not assume that the reader-philosopher has an adequate amount of information in the field of general topology, where the concepts considered are precisely defined. Although largely intuitive, the reasoning presented seems to be fundamentally correct and at the same time sufficient for our goal.

The modern concept of the infinite set is expressed by statements $(Z)$ and (D). If the choice is taken for granted, it is possible to demonstrate their equivalence. Therefore, statement $(Z)$ is equivalent to statement (D).

8 This is the generally accepted definition today.

9 This term was proposed by R. Dedekind (1831-1916). 
It is easy to see that statement (B) assigns actual existence to infinite sets. As we remember, statement (A) only ascribes potential existence to these sets. Consequently, proposal (B) can be considered as wider and more general than proposal (A).

It is also evident that the modern understanding of infinite sets refers to statement (B). It is therefore a continuation of the concept defined in (B). The fact that proposal (A) was rejected and that the modern thought refers to proposal (B) is an example of the undeniable progress that has been made in science (as far as the problem in question is concerned). The scientific thought has taken an important step forward by supporting statement (B). The concept of infinity, which takes the above-mentioned statement as its starting point, is a "more perfect" concept than the concept of infinity presented in statement $(A)$.

It should also be mentioned that the history of development of scientific research shows us that practical applications are born of purely scientific research, called basic research, conducted out of sheer cognitive curiosity. For example, in 1934 Cleeton and Williams studied the vibrations of the nitrogen atom in a molecule of ammonia. At the time, nobody needed it, neither was it useful for anything. But that is what led to the concept of the first maser. Thanks to the fact that some scientists conducted research on fluorescence and phosphorescence of chromium ions, a ruby laser was invented. Ruby is a mineral in which chromium ions are dispersed and produce fluorescence, which was the subject of research carried out by the aforementioned scientists. The results obtained led to the transformation of the entire global telecommunications system. This example shows us that it is worth supporting completely impractical research for practical purposes ${ }^{10}$. Given the above, it is possible to say that the technical and technological development is a sign of both development and progress in science.

This leads us to the question concerning the permanent elements in science, brought up in the introduction. Does progress in science exist together with the accumulation of knowledge and the preservation of at least some elements in it? Let us proceed to consider this matter.

10 A. H. Piekara, Nowe oblicze optyki, Warszawa 1968, 35. 


\section{PERMANENT ELEMENTS IN SCIENCE}

It seems most appropriate to address the problem we are interested in from a (let us call it) objective and historical point of view. We agreed that science is developing and that it is progressing in many different aspects. The question arises whether it is possible to indicate such scientific achievements that do not become obsolete and that constitute an integral and permanent part of modern science, in a convincing way, but without going into specialist details available only to specific individuals. Yes, in fact, it is possible to give a positive answer to the question raised and at the same time comply with the requirements of "availability" and "universality".

Let us first consider a very old field of knowledge, namely geometry. Its origins date back to very ancient times. The geometry system developed at that time is now called Euclidean geometry. It is taught in primary and secondary school. This geometry system was the only system known until the first quarter of the 19th century. In short, two systems of non-Euclidean geometry, i.e. elliptic geometry and hyperbolic geometry, were created later. Each of these three geometries does not contradict itself, but every two of them are mutually exclusive. The number of geometries increased from one to three, but it did not result in Euclidean geometry becoming outdated; it has retained its full scientific value until this day. Such development of geometry has enabled us to see its "essence" more broadly and better understand its "nature", which manifests itself not in one but in three forms. The progress made in geometry did not erase previous achievements and, as a result, did not exclude permanent elements from the geometry being developed.

Similarly, the differential and integral calculus of a function of one variable did not become obsolete once its generalizations relating to different abstract spaces had been created. What is more, if the said calculus did not exist for one variable, its generalizations would not have appeared. That is why, the calculus in question is not only a lasting achievement of the mathematical analysis, but also a starting point for future generalizations. 
When the notion of fuzzy sets ${ }^{11}$ was introduced, the classical definition of a set developed by Cantor, or the set theory based on this definition, did not become obsolete and the above-mentioned theory continues to be the fundamental branch of modern mathematics.

It is possible to give any number of such examples in this field due to the fact that mathematics is considered to be a typical branch of science where achievements are clearly accumulated.

Moreover, it seems that the situation is similar in other fields of knowledge. Another example is physics, which was extended with the quantum theory, relativity theory, and quantum mechanics in the 20th century. Such development did not however invalidate previous achievements of physics, which were and still are appreciated by the entire scientific community. Classical mechanics, statics of rigid bodies - these are simple examples of branches of physics that have both permanent theoretical values and numerous practical applications. The theory of evolution did not invalidate previous achievements in botany and zoology. In science, which is understood as a process and therefore considered to be in statu nascendi, incorrect suggestions and ideas may (and indeed do) appear. But later, new correct suggestions and ideas are put forward and accepted by the scientific community; finally, they become part of science as its lasting achievement. This issue is associated with Kuhn's concept of paradigm and its shift during the development of science.

However, this issue will not be discussed in detail, as it does not seem to be relevant to the question brought up in the article. We believe it is enough to mention the fact, which is general, yet recorded by history, that both truth and falsity belong to the history of science. Therefore, science is always a history of truth and error ${ }^{12}$.

Every scientist working in a particular discipline knows from his or her own experience that his or her discipline is a history of progress. However, it cannot be forgotten that an error, or overcoming it, makes

11 L. A. Zadeh, Fuzzy sets, Information and Control 8(1965), 338-353.

$12 \mathrm{~J}$. Mittelstrass, Vom Nutzen des Irrtums in der Wissenschaft, Naturwissenschaften 84(1997), 291; W. Ross Ashby, Wstęp do cybernetyki, transl. B. Osuchowska, A. Goosiewski, Warszawa 1963, 19. 
it possible to discover the truth, or to understand where it may be found. For this reason, an error belongs not only to the history of the error, but also to the history of progress in science. This is well illustrated by the distinction between the context of discovery and the context of justification. It better explains the issue related to the existence of progressive and permanent (retained, accumulated) components in scientific development. As shown, it not only does not exclude lasting scientific achievements but gradually increases their number.

\section{DIFFERENTIATION OF SCIENCE AND ITS UNITY}

Experience shows that the development of science is associated with an increase in the number of disciplines, specializations and their diversification. New, narrower specializations, which are almost hermetically separated from one another, are created and as a result, scientists stop understanding one another. This state of modern science seemed to be unavoidable. However, it turned out that this does not have to be like this at all. Cybernetics is an example of the branch of science which departed from this pattern. It proposed a common terminology for different types of research subjects, which had been considered to be completely different and impossible to compare until then ${ }^{13}$.

It can be shown on the example of cerebellar reflex and servomechanism. In the past they were considered to belong to separate and independent specializations, but cybernetics showed that the formal pattern is the same in each of these examples. After all, we already have a common language that can be used in many, very different areas of knowledge, such as, for instance, physiology, electronic circuits, and nervous system. The existence of permanent factors in science, which aim at creating elements integrating knowledge, has to be acknowledge at this point. This leads us to the issue of the unification of knowledge. Let us take a closer look at it.

Figuratively speaking, modern science, may be compared to a large net with a lot of meshes of different sizes. Some of them are divided 
into smaller meshes, others are joined by completely new meshes. The former give a deeper view of the original mesh, while the latter broaden the area of interest of science. The said net consists of a number of levels. The first level is followed by a higher level which is its scientific reflection. Science understood as a net develops in all directions. As a result, the number of higher levels may be increased, and issues may become more complex and subtle. The net in question also constitutes a certain whole. Experience shows that it is gradually becoming more and more coherent. This seems to be due to the fact that no issue is ever fully exhausted ${ }^{14}$. Of course, it can be solved at a given stage of scientific development, but it does not mean that it has been completely exhausted. The analysis of any scientific issue, as well as its solution, clearly indicates that it is connected with a number of other issues. The is always a network of connections between them. "Atomic" issues, issues completely separated from one another or issues that are, so to speak, absolute in themselves do not exist.

Science seen in this way is characterized by diversity, dynamism and lack of precisely defined boundaries between different disciplines or specializations. It seems that its dynamic nature determines its other features and leads to its further differentiation. Despite the fact that the number of scientific disciplines is constantly increasing, a trend towards the integration of science has emerged. Usually, this idea is presented using three levels or degrees ${ }^{15}$.

The uniformity of science is considered to be the lowest level. It is understood as a coherent, harmonized whole, something similar to a mosaic picture. Individual elements differ to some extent, but they form an indivisible composition. The unifying factor can be seen from a higher point of view, as if from the "outside". It can be called meta-eye ${ }^{16}$.

The integration of science is the second, higher level of its unification. It should be understood as some kind of connection between various

14 G. Polya, Jak to rozwiązać? Nowy aspekt metody matematycznej, transl. L. Kubik, Warszawa 1964, 35.

15 M. Lubański, S. W. Ślaga, Aspekt systemowy problemu jedności nauki, Studia Philosophiae Christianae 15(1979)1, 140, 142-144, 149.

16 Ibid, 149. 
fields of science that consists in complementing the research methods of one discipline with the research methods of other disciplines, i.e. in the "interpenetration of various fields of science". The genetic dependence existing between scientific disciplines should also be taken into account due to the fact that it undoubtedly leads to the integration of science. Moreover, there is also the phenomenon of cross-disciplinarity, also known as interdisciplinarity or more correctly transdisciplinarity, and the complementarity of disciplines in various forms and aspects. Overlapping scientific disciplines may be considered as a real manifestation of the tendency of modern science to integrate ${ }^{17}$.

The unity of science may be observed when various correlations (such as e.g. causal, functional, and teleological correlations etc.) occurring between any kind of phenomena are taken into account. In this case, it is necessary to adopt some basic epistemological unity which is not only not affected by various detailed research methods, but which is - or at least should be - reflected by such methods ${ }^{18}$.

The above-mentioned three levels of integration of modern science show it as a rich, complex system that aims at achieving unity combined with diversity. Today we understand better that unity does not have to exclude diversity. They can both complement each other.

\section{CONCLUSIONS}

The above discussion on science allows us to advance a thesis that progress in science exists together with conservatism. After all, not everything that is new is automatically scientifically valuable and therefore progressive in the best sense of the word. Similarly, not everything that is old is indisputable or impossible to be eliminated. Both must pass through the social control carried out by scientists in order to be approved and accepted as a solid scientific achievement. History shows that science preserves certain achievements and, at

\footnotetext{
17 Ibid, 150, 152.

18 Ibid, 152, 153.
} 
the same time, accepts and absorbs new elements. The new version of a scientific theory includes the results obtained in the past, which have stood the test of time.

Conservatism and progressiveness seem to be polar opposites in the development of science. Perhaps they reflect the features of a man who is both progressive and conservative. These qualities are reflected in science, the development of which does not involve rejecting everything that was achieved in the past. Innovation is combined with conservatism.

We have seen that progress in science is made in various forms, just like permanent elements in science are developed in many ways. The two components of science, i.e. progressive and conservative ones, exist together and emerge during its continuous development. Because science is always in statu fieri.

\section{BIBLIOGRAPHY}

Arystoteles, Fizyka, transl. K. Leśniak, Warszawa 1968.

Birkhoff G., Mac Lane S., Przegląd algebry wspótczesnej, transl. A. Ehrenfeucht, A. W. Mostowski, Warszawa 1966.

Bolzano B., Paradoxes of Infinity, transl. F. Prihonsky, Yale University Press, New Haven 1950.

Lubański M., Ślaga S. W., Aspekt systemowy problemu jedności nauki, Studia Philosophiae Christianae 15(1979)1,139-161.

Mittelstrass J., Vom Nutzen des Irrtums in der Wissenschaft, Naturwissenschaften 84(1997), 291-299.

Nalimow W.W., Mulczenko Z. M., Naukometria, transl. S. Zasada, Warszawa 1971.

Piekara A. H., Nowe oblicze optyki, Warszawa 1968.

Polya G., Jak to rozwiazać? Nowy aspekt metody matematycznej, transl. L. Kubik, Warszawa 1964.

Ratajewski J., Wstęp do informacji naukowej, Katowice 1973.

Ross Ashby W., Wstęp do cybernetyki, transl. B. Osuchowska, A. Goosiewski, Warszawa 1963.

Solla Price D. J. de, Wętowe problemy historii nauki, transl. H. Krahelska, Warszawa 1965. 
Uklejska M., Zarys rozwoju nauki i jej organizacji, Część II: Czasy nowożytne, Warszawa 1963.

Zadeh L. A., Fuzzy sets, Information and Control 8(1965), 338-353.

Mieczysław Lubański

DOI: $10.21697 /$ spch.2020.56.S2.01 